\title{
Selenols are Resistant to Irreversible Modification by HNO
}

\author{
Christopher L. Bianco ${ }^{\mathrm{a}}$, Cathy D. Moore ${ }^{\mathrm{a}}$, Jon M. Fukuto ${ }^{\mathrm{b}}$, John P. Toscano ${ }^{\mathrm{a}, *}$ \\ ${ }^{a}$ Department of Chemistry, Johns Hopkins University, 3400 N. Charles St., Baltimore, \\ Maryland 21218 USA. \\ ${ }^{b}$ Department of Chemistry, Sonoma State University, 1801 E. Cotati Ave., Rohnert Park, \\ California 94928 USA
}

*Corresponding author.

E-mail address: jtoscano@jhu.edu 


\section{Graphical Abstract}

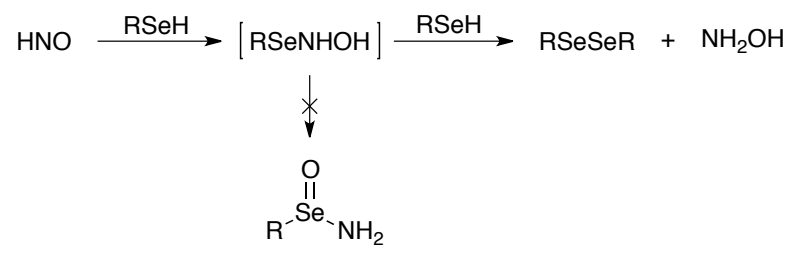




\begin{abstract}
The discovery of nitric oxide (NO) as an endogenously generated signaling species in mammalian cells has spawned a vast interest in the study of the chemical biology of nitrogen oxides. Of these, nitroxyl (azanone, HNO) has gained much attention for its potential role as a therapeutic for cardiovascular disease. Known targets of HNO include hemes/heme proteins and thiols/thiol-containing proteins. Recently, due to their roles in redox signaling and cellular defense, selenols and selenoproteins have also been speculated to be additional potential targets of HNO. Indeed, as determined in the current work, selenols are targeted by HNO. Such reactions appear to result only in formation of diselenide products, which can be easily reverted back to the free selenol. This characteristic is distinct from the reaction of $\mathrm{HNO}$ with thiols/thiolproteins. These findings suggest that, unlike thiolproteins, selenoproteins are resistant to irreversible oxidative modification, indicating that Nature may have chosen to use selenium, instead of sulfur, in certain biological systems for this reason.
\end{abstract}

Keywords: selenium, selenol, selenoenzymes, diselenide, seleninamide, $N$ hydroxyselenenamide, nitroxyl, thiol, disulfide, sulfinamide, $N$-hydroxysulfenamide, cysteine, selenocysteine, benzeneselenol

\footnotetext{
Abbreviations: Angeli's salt (AS), 2-bromopiloty's acid (2-BrPA), selenol (RSeH), selenocysteine ( $\mathrm{Sec}$ ), selenocystine $\left(\mathrm{Sec}_{2}\right), N$-hydroxyselenenamide (RSeNHOH), seleneninamide $\left(\mathrm{RSe}(\mathrm{O}) \mathrm{NH}_{2}\right), 5,5$ '-Dithiobis(2-nitrobenzoic acid) (DTNB), cysteine $\left(\mathrm{Cys}_{2}\right)$, glutathione peroxidase (GPx), $o$-nitrophenylselenol (o-NPS), bis(o-nitrophenyl) diselenide (o-NPdS), benzeneselenol $(\mathrm{PhSeH})$, diphenyl diselenide $(\mathrm{PhSeSePh})$, selenocysteine methyl ester $(\mathrm{SecOMe})$, selenocystine dimethyl ester $\left(\mathrm{SecOMe}_{2}\right)$
} 


\section{Introduction}

Nitroxyl (HNO) is the one electron reduced and protonated congener of nitric oxide (NO). Like NO, HNO has gained much interest for its effects on the cardiovascular system, especially for its potential as a therapeutic agent to treat heart failure. $^{1-4}$ Importantly, the reactivity of HNO is distinct from that of NO. For example, HNO does not have an unpaired electron and is therefore not expected to react with radical species via direct radical-radical interactions. Additionally, NO and HNO are both known to react with heme-containing proteins; however, NO preferentially favors ferrous hemes whereas HNO favors ferric hemes. ${ }^{5}$ Other targets of HNO, which are of more relevance to the current study, are thiols and thiol-containing proteins. ${ }^{6,7}$

In general, HNO-induced modification of thiols follows two primary pathways (Scheme 1), ultimately leading to the corresponding disulfide (RSSR') and/or sulfinamide $\left(\mathrm{RS}(\mathrm{O}) \mathrm{NH}_{2}\right){ }^{8-10}$ The initial reaction of $\mathrm{HNO}$ with a thiol results in an $\mathrm{N}$ hydroxysulfenamide intermediate $(\mathrm{RSNHOH}) .{ }^{8,9}$ In the presence of excess thiol (RSH), the $N$-hydroxysulfenamide reacts with a second equivalent of thiol to form the corresponding disulfide ${ }^{8,9}$ (Scheme 1, Pathway A). Alternatively, if thiol concentrations are limited, the $N$-hydroxysulfenamide undergoes rearrangement to the corresponding sulfinamide $^{8-13}$ (Scheme 1, Pathway B). Thiol modification to a disulfide is considered to be biologically reversible as disulfides are readily reduced in the presence of biological reductants. ${ }^{8,9}$ However, thiol modification to the sulfinamide has been traditionally considered to be irreversible, though recent studies have shown that reduction of the sulfinamide is possible, albeit slow. ${ }^{11-17}$ 


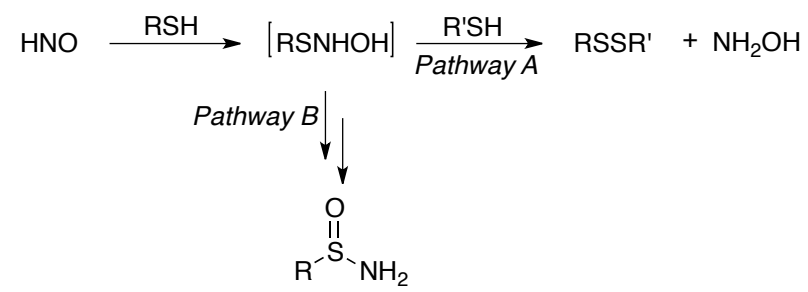

Scheme 1: Pathways for the reaction of HNO with thiols

Like thiols, selenols are also biologically relevant species with critical roles in redox signaling. Regarded as the $21^{\text {st }}$ amino acid, selenocysteine (Sec) is the seleniumcontaining analogue of cysteine (Cys). ${ }^{18}$ Currently, three main classes of enzymes have been identified that contain selenocysteine within the active site. These enzymes include the glutathione peroxidases (GPx), thioredoxin reductases (TrxR), and iodothyronine deiodinases (DIO). ${ }^{19}$ Each of these enzyme classes relies on a selenocysteine residue for catalysis, most of which involve antioxidant functions. For example, GPx catalyzes the reduction of hydrogen peroxide and alkylhydroperoxides. ${ }^{20}$ TrxR is the only known enzyme to reduce oxidized thioredoxin (Trx), which has a number of significant roles in redox signaling. ${ }^{21}$ DIO catalyzes the deiodination of the inactive thyroid hormone, $\mathrm{T}_{4}$, to the active hormone, $\mathrm{T}_{3}$, which has been reported to have roles in cardiovascular function and metabolism.

Compared with thiols, selenols have enhanced nucleophilicity and reducing capabilities. $^{22,23}$ For example, Sec has a $\mathrm{pK}_{\mathrm{a}}$ of 5.2 and a reduction potential ( and a reduction potential (cystine $\left(\mathrm{Cys}_{2}\right) / \mathrm{Cys}$ ) of $-0.223 \mathrm{~V}$ under analogous conditions. ${ }^{18,22,23}$ Thus, under physiological conditions, free Sec is primarily deprotonated, whereas free Cys is primarily protonated, though protein environments 
may influence these protonation states. Based on this expected reactivity, selenols, like thiols, are anticipated not only to have the ability to trap HNO, but may also be more potent in trapping HNO compared with analogous thiol species.

Importantly, selenium has an NMR active isotope, selenium-77 (quantum spin number $=1 / 2$ ), which is very diagnostic in characterizing various selenium species. ${ }^{24}$ Selenium NMR has a chemical shift range of about 3300 ppm, allowing facile identification of unknown selenol species even within complex mixtures. ${ }^{25,26}$ For example, benzeneselenol (PhSeH) has a chemical shift of 152 ppm, whereas diphenyl diselenide $(\mathrm{PhSeSePh})$ and benzeneseleninic acid $(\mathrm{PhSe}(\mathrm{O}) \mathrm{OH})$ have chemical shifts of 450 and $1170 \mathrm{ppm}$, respectively in DMSO- $d_{6} \cdot{ }^{25,27}$ The current study aims to determine if indeed selenols are possible (if not primary) biological targets for HNO and, with the use of ${ }^{77}$ Se NMR along with other analytical methods, if the products of such interactions are analogous to those found for the reaction of thiols with HNO.

\section{Experimental Procedures}

\section{Materials}

Reagents. Diphenyl diselenide, seleno-L-cystine, selenious acid, methyl selenide, hydrogen peroxide solution, $o$-nitroaniline, boron trifluoride diethyl etherate, butyl nitrite, potassium selenocyanate $(\mathrm{KSeCN})$, sodium metal, L-cysteine and, 5,5'-dithiobis(2nitrobenzoic acid) (DTNB), were purchased from Sigma (St. Louis, MO). Sodium borohydride $\left(\mathrm{NaBH}_{4}\right)$ was purchased from Acros. HPLC grade methanol was purchased from Thermo Fisher Scientific (Rockland, IL). Dimethyl sulfoxide- $d_{6}\left(\mathrm{DMSO}-d_{6}\right), \mathrm{D}_{2} \mathrm{O}$ 
and, chloroform- $d\left(\mathrm{CDCl}_{3}\right)$ was purchased from Cambridge Isotope Laboratories (Andover, MA). The HNO donors, Angeli's salt $\left(\mathrm{Na}_{2} \mathrm{~N}_{2} \mathrm{O}_{3}, \mathrm{AS}\right.$ ) and 2bromohydroxybenzenesulfonamide (2-BrPA) were prepared as previously described. ${ }^{28-30}$

Preparation of cysteine methyl ester. The procedures of Li and Sha were followed with slight modification. ${ }^{31}$ Briefly, L-cysteine $(0.08 \mathrm{mmol})$ was dissolved in methanol $(25 \mathrm{~mL})$, hydrochloric acid $(1 \mathrm{~mL})$ was added to the solution, and the mixture was refluxed overnight. The mixture was then concentrated by rotatory evaporation, yielding an oil. The oil was titerated with diethyl ether and dried overnight to give Lcysteine methyl ester as a white solid $(0.135 \mathrm{~g}, 96 \%$ yield $):{ }^{1} \mathrm{H}-\mathrm{NMR}\left(\mathrm{D}_{2} \mathrm{O}\right) \delta 4.53(\mathrm{t}$, 1H), $3.97(\mathrm{~s}, 3 \mathrm{H}), 3.33-3.21(\mathrm{~m}, 2 \mathrm{H})$.

Preparation of selenocystine dimethyl ester p-toluenesulfonate. The methods of Haratake et al were followed. ${ }^{32}$ Briefly, seleno-l-cystine $(0.3 \mathrm{mmol})$ was dissolved in methanol (10 $\mathrm{mL}), p$-toluenesulfonic acid monohydrate $(5 \mathrm{mmol})$ was added, and the mixture refluxed overnight. The solvent was removed via rotatory evaporation and the resulting sticky solid was allowed to sit overnight in diethyl ether. The ether was then decanted and the solid was dried overnight to give seleno-L-cysteine dimethyl ester $p$ toluenesulfonate $\left(\mathrm{SecOMe}_{2}\right)$ as an off-white solid (0.205 g, $97 \%$ yield): ${ }^{1} \mathrm{H}-\mathrm{NMR}$ $\left(\mathrm{DMSO}-d_{6}\right) \delta 4.51(\mathrm{t}, 1 \mathrm{H}), 3.95(\mathrm{~s}, 3 \mathrm{H}), 3.68-3.51(\mathrm{~m}, 2 \mathrm{H}) ;{ }^{77} \mathrm{Se}-\mathrm{NMR}$ (DMSO- $d_{6}$, relative to methyl selenide) $\delta 297.91$. 
Synthesis of of bis(o-nitrophenyl)diselenide. The procedures of Casar et al. were followed. ${ }^{33} o$-Nitroaniline $(17 \mathrm{mmol})$ was dissolved in dry dichloromethane $(25 \mathrm{~mL})$ at $15^{\circ} \mathrm{C}$. Boron trufluoride diethyl etherate $(3.5 \mathrm{~mL})$ was added dropwise and the mixture stirred for 15 minutes. A solution of butyl nitrite $(22.5 \mathrm{mmol})$ in dry dichloromethane $(10 \mathrm{~mL})$ was then added dropwise and the mixture stirred 30 minutes at $-15^{\circ} \mathrm{C}$, and an additional 30 minutes at $0{ }^{\circ} \mathrm{C}$. Cold pentane $(20 \mathrm{~mL})$ was added and the solution filtered. The precipitate was washed with cold ether $(200 \mathrm{~mL})$. The collected solid was then dissolved in water $(80 \mathrm{~mL})$ on ice bath and a solution of $\mathrm{KSeCN}(17 \mathrm{mmol})$ in water $(20$ $\mathrm{mL}$ ) was added over 10 minutes. After complete addition of the $\mathrm{KSeCN}$ solution, the mixture was stirred for an additional 10 minutes. The precipitate was then filtered and collected. The solid was re-dissolved in ethanol $(60 \mathrm{~mL})$ and sodium metal $(17 \mathrm{mmol})$ was added portionwise. The mixture was allowed to stir for 2 hours at which time the precipitate was filtered, washed with ethanol $(120 \mathrm{~mL})$, and allowed to dry overnight to give bis(o-nitrophenyl)diselenide (o-NPdS, $3.0 \mathrm{~g}, 88 \%$ yield): ${ }^{1} \mathrm{H}-\mathrm{NMR}\left(\mathrm{CDCl}_{3}\right) \delta 8.39$ $(\mathrm{d}, 2 \mathrm{H}), 7.92(\mathrm{~d}, 2 \mathrm{H}), 7.54-7.42(\mathrm{~m}, 4 \mathrm{H}) ;{ }^{77} \mathrm{Se}-\mathrm{NMR}\left(\mathrm{CDCl}_{3}\right.$, relative to methyl selenide) $\delta 484.37,{ }^{77} \mathrm{Se}$ NMR (DMSO- $d_{6}$, relative to methyl selenide) $\delta 478.76$.

Preparation of selenols. Selenols were prepared by reduction of the corresponding diselenides. Diphenyl diselenide (PhSeSePh), o-NPdS, and $\mathrm{SecOMe}_{2}$ all followed the same procedures for reduction of the diselenide and quantification of the resulting free selenol. Each diselenide $(0.01$ to $0.05 \mathrm{mmol})$ was dissolved in ethanol (5 $\mathrm{mL}$ ) and 10-times excess $\mathrm{NaBH}_{4}$ was added. ${ }^{23,27}$ The reductions were allowed to proceed under an atmosphere of nitrogen for 30 minutes, at which time the solutions became 
colorless. The reductions were quenched by slow addition of acetic acid $(70 \mu \mathrm{L})$, which had been previously purged with nitrogen. Samples were kept under an atmosphere of nitrogen and used within 1 hour of reduction without further purification.

\section{Methods}

DTNB quantification of diselenide reduction. 5,5'-Dithiobis(2-nitrobenzoic acid) (DTNB), otherwise known as Ellman's reagent, is a common reagent used for the quantification of free thiol species. ${ }^{34}$ Quantification of free thiols was determined by monitoring the increase in absorbance at $\lambda_{\max }=412 \mathrm{~nm}$, which is due to the liberation of 2-nitro-5-thiobenzoate (TNB) upon reaction of nucleophilic thiol species with DTNB. Likewise, the quantification of free selenol species can be determined with use of DTNB, which also liberates TNB upon reaction with free selenols. To quantify free selenol concentrations, quartz cuvettes containing $3 \mathrm{~mL}$ of $100 \mathrm{mM}$ phosphate buffer ( $\mathrm{pH}$ 7.4) with $50 \mu \mathrm{M}$ of the metal chelator, diethylenetriaminepentaacetic acid (DTPA), were fitted with rubber septa and purged with argon for 30 minutes. The cuvettes were then incubated at $37{ }^{\circ} \mathrm{C}$ for 10 minutes at which time $20 \mu \mathrm{L}$ of the individual stock selenol solutions (as described above) were added via syringe. Each sample was immediately titrated with a solution of DTNB $(2.5 \mathrm{mM})$ in phosphate buffer previously purged with argon. The extent of reduction was quantified by monitoring the increase in UV absorbance of TNB $\left(\varepsilon_{412}=14150 \mathrm{M}^{-1} \mathrm{~cm}^{-1}\right) .{ }^{34}$

GC headspace analysis of selenol incubations with AS. In the absence of chemical traps, HNO undergoes rapid dimerization, ultimately forming nitrous oxide 
$\left(\mathrm{N}_{2} \mathrm{O}\right)$ and water. ${ }^{35}$ However, in the presence of chemical traps like thiols and selenols, trapping of HNO becomes a competitive reaction pathway with HNO dimerization. ${ }^{36-39}$ The extent of HNO trapping by thiols and selenols can be determined by measuring the reduction in $\mathrm{N}_{2} \mathrm{O}$ production (relative to that observed for AS only) upon addition of thiols or selenols. Thus, HNO trapping by selenols was examined by preparing four separate vials with $5 \mathrm{~mL}$ of $100 \mathrm{mM}$ phosphate buffer $(\mathrm{pH}$ 7.4) containing $50 \mu \mathrm{M}$ DTPA fitted with rubber septa and purged with argon for 30 minutes. A stock solution of benzeneselenol ( $\mathrm{PhSeH}$, prepared as above) was then diluted into each of the four vials to final concentrations of $0.05,0.1,0.2$ and $0.5 \mathrm{mM}$, respectively. Next, $100 \mu \mathrm{L}$ of a $5 \mathrm{mM}$ stock solution of AS in $0.01 \mathrm{M} \mathrm{NaOH}$ purged with argon was added to each of the four vials (final $[\mathrm{AS}]=100 \mu \mathrm{M}$ ). The vials were then incubated at $37^{\circ} \mathrm{C}$ in a block heater for 2 hours. To serve as a standard, an additional fifth vial was filled with the same volume of buffer under argon and AS only was added.

For comparison, thiophenol ( $\mathrm{PhSH})$ was also incubated with AS. Stock solutions were prepared by dissolving $\mathrm{PhSH}$ in ethanol and purging the solution with nitrogen for 30 minutes. Free thiol concentration was quantified by analogous DTNB analysis (described above). Incubations of PhSH with AS were carried out under the same conditions as $\mathrm{PhSeH}$, using the same AS stock solution.

Aliquots $(60 \mu \mathrm{L})$ of headspace from all vials were analyzed for $\mathrm{N}_{2} \mathrm{O}$ production via gas chromatography (GC). ${ }^{36-39}$ As controls, incubations for $\mathrm{PhSeH}$ and $\mathrm{PhSH}$ were also carried out with the AS byproduct, nitrite $\left(\mathrm{NO}_{2}{ }^{-}\right)$, under the same conditions. Free selenol or thiol concentration was also quantified by DTNB analysis post incubation for all reaction mixtures and controls. 
NMR analysis of selenol incubations with 2-BrPA. A $250 \mathrm{~mL}$ round bottom flask containing $190 \mathrm{~mL}$ of $100 \mathrm{mM}$ phosphate buffer (pH 7.4) with $50 \mu \mathrm{M}$ DTPA was fitted with a rubber septum and purged with nitrogen for 1 hour. Stock solutions of selenols (prepared as above) were transferred to the flask of buffer via cannula. All incubations were performed at a final selenol concentration of $250 \mu \mathrm{M}$. Next, $5 \mathrm{~mL}$ of a $100 \mathrm{mM}$ stock solution of 2-BrPA in acetonitrile previously purged with nitrogen was added to the buffer flask via cannula (final $[2-\mathrm{BrPA}]=2.5 \mathrm{mM}$ ). The mixture was then incubated at $37^{\circ} \mathrm{C}$ in a temperature-controlled water bath for 2 hours. After incubation, the solution was frozen at $-80{ }^{\circ} \mathrm{C}$ and the solvent lyophilized. The remaining solid was re-dissolved in a 50:50 dichloromethane:methanol mixture and filtered. The filtrate was collected and concentrated by rotatory evaporation. The remaining solid was analyzed by NMR spectroscopy in DMSO- $d_{6}$. As controls, $\mathrm{PhSeH}$ was also incubated with the byproduct of 2-BrPA, 2-bromobenzenesulfinic acid, or alone under the same conditions. Free selenol concentrations were quantified by DTNB analysis post incubation for all reaction mixtures and controls.

For ${ }^{77}$ Se-NMR analyses, a $3.30 \mathrm{~mm}$ coaxial insert tube (Wilmad-Labglass, Vineland, NJ) was placed in a $5 \mathrm{~mm}$ NMR outer tube containing the analyte solution. The coaxial insert tubes contained either $11.5 \mathrm{M}$ selenious acid in $\mathrm{D}_{2} \mathrm{O}$ or neat methyl selenide (as indicated in the results) as external references. All ${ }^{1} \mathrm{H}-\mathrm{NMR}$ and ${ }^{77} \mathrm{Se}-\mathrm{NMR}$ analyses were carried out on a Bruker Avance 400 MHz FT-NMR spectrometer. All chemical shifts are reported in parts per million (ppm). ${ }^{1} \mathrm{H}-\mathrm{NMR}$ chemical shifts are relative to the indicated deuterated solvents. ${ }^{77} \mathrm{Se}-\mathrm{NMR}$ chemical shifts are relative to 
either selenious acid (1300 ppm) or methyl selenide (0 ppm) external standards, as indicated in the results. ${ }^{40,41}$

HPLC analysis of selenol incubations with AS. Two separate vials were prepared for each selenol. Each vial contained $5 \mathrm{~mL}$ of $100 \mathrm{mM}$ phosphate buffer (pH 7.4) with $50 \mu \mathrm{M}$ DTPA. The vials were fitted with rubber septa and purged with argon for 30 minutes. Stock solutions of each selenol (prepared as above) were added to the two vials to final concentrations of $100 \mu \mathrm{M}$ in each vial. Next, $10 \mu \mathrm{L}$ of a $50 \mathrm{mM}$ AS stock solution in $0.01 \mathrm{M} \mathrm{NaOH}$ previously purged with argon was added to one vial and $100 \mu$ L of the same AS stock solution was added to the second vial (final $[\mathrm{AS}]=100 \mu \mathrm{M}$ and 1 $\mathrm{mM}$, respectively). The vials were incubated at $37^{\circ} \mathrm{C}$ in a block heater for 2 hours.

Aliquots of each mixture were analyzed by HPLC (Waters HPLC system equipped with a Delta 600 pump system and a dual-wavelength absorbance detector) on an Apollo $\mathrm{C}_{18}$ reverse phase column using an isocratic gradient of $85 \%$ methanol with $0.1 \%$ trifluoroacetic acid (TFA) at $40{ }^{\circ} \mathrm{C}$. Samples containing $\mathrm{PhSeH}$ and $o$ nitrophenylselenol (o-NPS) were followed at $254 \mathrm{~nm}$. Samples containing Lselenocysteine (SecOMe) were followed at $220 \mathrm{~nm}$. All peaks were assigned by comparison with authentic samples.

Detection of HNO-derived products via ESI-MS. A stock solution (5 mM) of $\mathrm{PhSeH}$ was prepared in phosphate buffer as indicated above. AS was diluted in $0.01 \mathrm{M}$ $\mathrm{NaOH}$ to a final concentration of $50 \mathrm{mM}$ and purged with $\mathrm{N}_{2}$ for 30 minutes. $\mathrm{PhSeH}$ was diluted in $\mathrm{N}_{2}$-purged $100 \mathrm{mM}$ ammonium bicarbonate buffer ( $\mathrm{pH}$ 7.4) containing $50 \mu \mathrm{M}$ 
DTPA to a final concentration of $100 \mu \mathrm{M}$. The mixture was equilibrated to $37^{\circ} \mathrm{C}$. AS was then added to a final concentration of $1 \mathrm{mM}$. Reactions were allowed to proceed at $37^{\circ} \mathrm{C}$ for 2 hours at which time $50 \mu \mathrm{L}$ aliquots of the reaction mixture were mixed with $250 \mu \mathrm{L}$ of methanol and injected directly into a Thermo TSQ Quantum Triple Quadrupole Mass Spectrometer controlled with XCalibur 2.1 via syringe pump. Spectra were acquired in positive ion mode with a spray voltage of $3500 \mathrm{~V}$, a capillary temperature of $250^{\circ} \mathrm{C}$, and a flow rate of $1 \mu \mathrm{L} / \mathrm{min}$. Ion optics were optimized for all ions of interest.

Computational Analysis. Calculations were performed with Spartan ' $14 .{ }^{42}$ Geometries were fully optimized at the B3LYP level of theory with the 6-31G(d) or 6311(d,p) basis set as indicated. Vibrational frequencies were also calculated to verify minimum energy structures (no imaginary frequencies) or transition states (one imaginary frequency) and to provide zero-point vibrational energy corrections. Examination of the lowest energy conformations of reactants/products and transition states for the reaction of $\mathrm{HNO}$ with either PhSeH or PhSH followed the work of McCulla and co-workers. ${ }^{43}$ For reactions involving $\mathrm{PhSH}$ and $\mathrm{HNO}$, the coordinates reported by McCulla and co-workers were used as a staring point for energy optimization at the B3LYP/6-31G(d) level of theory. For calculations involving selenium, the basis set was expanded to $6-311 \mathrm{G}(\mathrm{d}, \mathrm{p})$ and the lowest energy conformations and transition states were re-optimized. For reactions involving benzeneselenol and $\mathrm{HNO}$, optimizations were started from the geometries of the analogous thiol structures. 


\section{Results}

GC headspace analysis of selenol incubations with AS. Initially, the ability of selenols to trap HNO was investigated by examining the yield of the product of HNO dimerization $\left(\mathrm{N}_{2} \mathrm{O}\right)$ as a function of selenol concentration. For comparison, analogous experiments were also carried out with the corresponding thiol. As shown in Figure 1 (grey bars), incubations of $100 \mu \mathrm{M}$ AS with varying concentrations of $\mathrm{PhSeH}$ indicate that indeed $\mathrm{PhSeH}$ traps $\mathrm{HNO}$. This is consistent with the marked decrease in $\mathrm{N}_{2} \mathrm{O}$ production (relative to AS only) upon increasing addition of $\mathrm{PhSeH}$. Likewise, additions of the analogous thiol, $\mathrm{PhSH}$, to buffer solutions containing $100 \mu \mathrm{M}$ AS also result in a decrease in $\mathrm{N}_{2} \mathrm{O}$ production (Figure 1, black bars), relative to AS only. Trapping of $\mathrm{HNO}$ by both $\mathrm{PhSeH}$ and $\mathrm{PhSH}$ exhibited a concentration-dependence, with $\mathrm{PhSeH}$ having a greater apparent affinity for $\mathrm{HNO}$ than $\mathrm{PhSH}$ under the same reaction conditions, as indicated by a greater decrease in $\mathrm{N}_{2} \mathrm{O}$ production in the presence of equal concentrations of $\mathrm{PhSeH}$ versus $\mathrm{PhSH}$. ( $\mathrm{PhSeH}$ did not react with the $\mathrm{AS}$ byproduct, $\mathrm{NO}_{2}{ }^{-}$, under analogous reaction conditions.)

It should be noted that at $\mathrm{pH} 7.4, \mathrm{PhSeH}\left(\mathrm{pK}_{\mathrm{a}}=5.9\right)$ is mostly deprotonated, whereas $\mathrm{PhSH}\left(\mathrm{pK}_{\mathrm{a}}=6.6\right)$ is less so. Thus, the overall increase in the observed reactivity of $\mathrm{PhSeH}$ vs. $\mathrm{PhSH}$ with $\mathrm{HNO}$ is partially due to the greater amount of anion present under the experimental conditions ( $\mathrm{pH}$ 7.4). Since the selenolate and thiolate are expected to be much more reactive than the corresponding selenol and thiol, an environment that regulates the protonation state of these species (i.e., proteins) would be expected to influence the relative reactivity of selenols and thiols. 


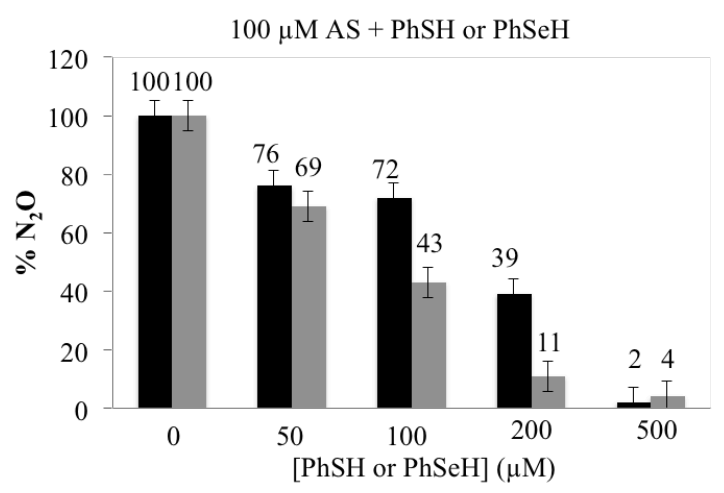

Figure 1: Yield of $\mathrm{N}_{2} \mathrm{O}$ in the presence of increasing concentrations of $\mathrm{HNO}$ traps, $\mathrm{PhSeH}$ (grey bars) and $\mathrm{PhSH}$ (black bars). Incubations were performed with $0,50,100,200$, and $500 \mu \mathrm{M} \mathrm{PhSeH}$ or $\mathrm{PhSH}$ and 100 $\mu \mathrm{M}$ AS in $100 \mathrm{mM}$ phosphate buffer (pH 7.4) with $50 \mu \mathrm{M}$ DTPA at $37^{\circ} \mathrm{C}$ for 2 hours. Values are reported as percentage of $\mathrm{N}_{2} \mathrm{O}$ (product of $\mathrm{HNO}$ dimerization) produced upon the addition of increasing amounts of HNO trap relative to incubation of $100 \mu \mathrm{M}$ AS only $\left(100 \% \mathrm{~N}_{2} \mathrm{O}\right)$.

NMR analysis of selenol incubations with 2-BrPA. The data of Figure 1 indicate that the selenol $\mathrm{PhSeH}$ reacts readily with $\mathrm{HNO}$ (and to a greater extent than the corresponding thiol, $\mathrm{PhSH})$. Thus, it became important to then determine whether the reactions of selenols with $\mathrm{HNO}$ are analogous to those already established for thiols. Samples of selenols were therefore incubated with the HNO donor, 2-BrPA, and analyzed by ${ }^{77}$ Se NMR (Figure 2). Excess HNO donor was used as an attempt to mimic similar previously studied thiol-HNO reactions, which primarily result in sulfinamide formation when $\mathrm{HNO}$ is in excess. ${ }^{9,14}$ Incubation of $250 \mu \mathrm{M}$ PhSeH with $2.5 \mathrm{mM}$ 2-BrPA results in the formation of a single selenium species with a ${ }^{77} \mathrm{Se}$ NMR chemical shift at $448.80 \mathrm{ppm}$ (referenced to methyl selenide ${ }^{41}$ ) in DMSO- $d_{6}$ (Figure 2a). Comparison of the measured spectrum with that of an authentic sample confirms the presence of $\mathrm{PhSeSePh}$ as the only product in the reaction mixture. Additionally, both $o$-NPS $(250 \mu \mathrm{M})$ and SecOMe $(250$ $\mu \mathrm{M}$ ) were incubated with $2.5 \mathrm{mM}$ 2-BrPA under the same conditions as $\mathrm{PhSeH}$. 
Incubation of $o$-NPS with 2-BrPA yields a single selenium species with a ${ }^{77} \mathrm{Se}$ NMR chemical shift at $478.70 \mathrm{ppm}$ in DMSO- $d_{6}$ (Figure 2b). Likewise, incubation of SecOMe with 2-BrPA also yields a single selenium species with a ${ }^{77}$ Se NMR chemical shift at 298 ppm in DMSO- $d_{6}$ (Figure 2c). Again, comparison with authentic samples verifies that incubations of both $o$-NPS and SecOMe with 2-BrPA result in the formation of the corresponding diselenide species only.
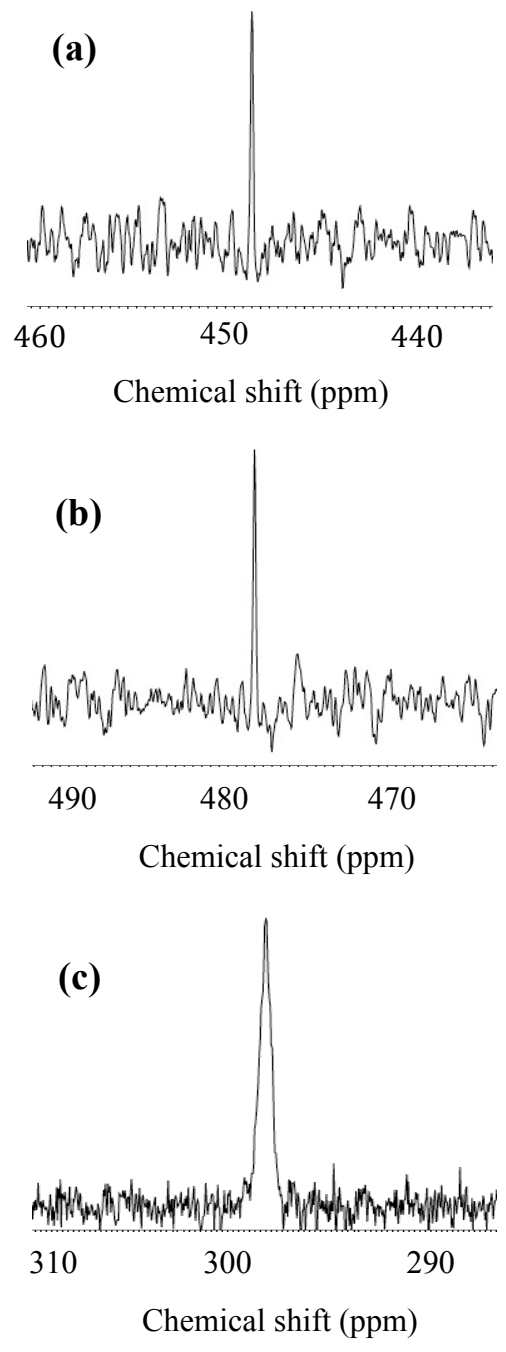

Figure 2: Selected region of ${ }^{77} \mathrm{Se}$ NMR spectrum for incubations of selenols $(250 \mu \mathrm{M})$ with 2-BrPA $(2.5$ $\mathrm{mM}$ ) in $100 \mathrm{mM}$ phosphate buffer (pH 7.4) with $50 \mu \mathrm{M}$ DTPA at $37^{\circ} \mathrm{C}$ for 2 hours. (a) Incubation of $\mathrm{PhSeH}$ with 2-BrPA. The peak at $448.80 \mathrm{ppm}$ corresponds to PhSeSePh. (b) Incubation of $o$-NPS with 2- 
BrPA. The peak at $478.70 \mathrm{ppm}$ corresponds to $o-\mathrm{NPdS}$. (c) Incubation of $\mathrm{SecOMe}_{2}$ with 2-BrPA. The peak at 298 ppm corresponds to $\mathrm{SecOMe}_{2}$.

HPLC analysis of selenol incubations with AS. The previous NMR data implies that unlike reactions of thiols with $\mathrm{HNO}$, which can result in either a disulfide or a rearranged sulfinamide, reactions of selenols with $\mathrm{HNO}$ result in the corresponding diselenide only. To confirm this observation, products formed following incubations of selenols with HNO were examined by HPLC. HPLC analysis of reaction mixtures containing $100 \mu \mathrm{M}$ PhSeH and either $100 \mu \mathrm{M}$ or $1 \mathrm{mM}$ AS verified the presence of only one product (Figure 3a) post incubation. Comparison of this species with an authentic sample verifies its identity as PhSeSePh. Additionally, incubations of both $o$-NPS (100 $\mu \mathrm{M})$ and SecOMe $(100 \mu \mathrm{M})$ with $100 \mu \mathrm{M}$ and $1 \mathrm{mM}$ AS were analyzed. Under all conditions, incubation of AS with $o$-NPS or SecOMe yielded $o$-NPdS (Figure 3b) or $\mathrm{SecOMe}_{2}$ (Figure 3c) only, respectively. 

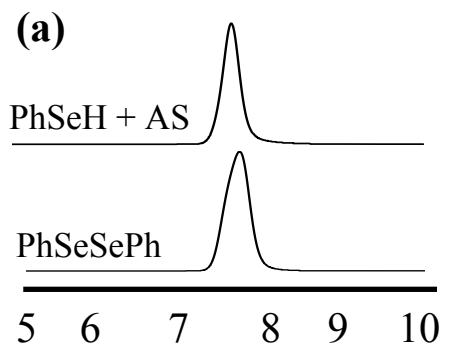

Retention time (min)
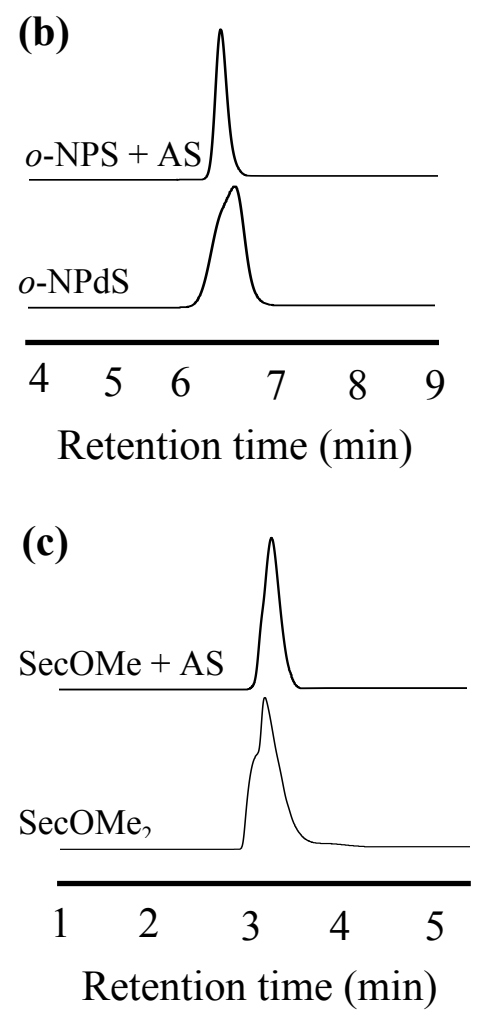

Figure 3: HPLC analysis for the characterization of products formed from incubations of selenols (100 $\mu \mathrm{M})$ with AS (1 mM) in $100 \mathrm{mM}$ phosphate buffer (pH 7.4) with $50 \mu \mathrm{M}$ DTPA at $37{ }^{\circ} \mathrm{C}$ for 2 hours.

Retention times for (a) authentic $\mathrm{PhSeSePh}$ (lower) and $\mathrm{PhSeSePh}$ formed from incubation of $\mathrm{PhSeH}$ with AS (upper), (b) $o$-NPdS (lower) and $o$-NPdS formed from incubation of $o$-NPS with AS (upper) and, (c) $\mathrm{SecOMe}_{2}$ (lower) and $\mathrm{SecOMe}_{2}$ formed from incubation of SecOMe with AS (upper) are given. 
Detection of HNO-derived products via ESI-MS. To confirm further that HNOinduced modification of selenols results in the formation of the corresponding diselenide only, product analysis for the reaction of $\mathrm{PhSeH}$ and AS was performed by electrospray ionization mass spectrometry (ESI-MS). Figure 4 displays the mass spectrum of the product that results from the reaction of $1 \mathrm{mM} \mathrm{AS}$ with $100 \mu \mathrm{M} \mathrm{PhSeH}$.

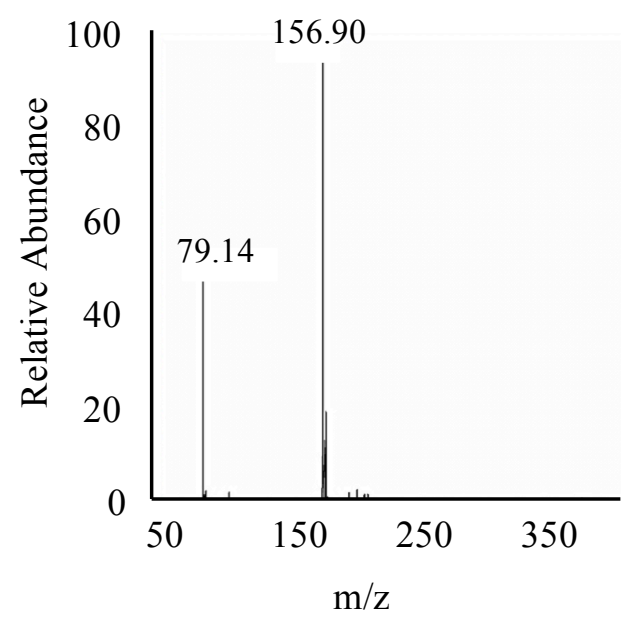

Figure 4: ESI-MS resulting from the reaction of $1 \mathrm{mM} \mathrm{AS}$ and $100 \mu \mathrm{M} \mathrm{PhSeH}$ in $100 \mathrm{mM}$ ammonium bicarbonate buffer ( $\mathrm{pH} 7.4$ ) with $50 \mu \mathrm{M}$ DTPA. The peak at $156.97 \mathrm{~m} / \mathrm{z}$ corresponds to the daughter ion $[\mathrm{M}-\mathrm{PhSeH}]^{+}$resulting from cleavage of the Se-Se bond.

The peak at $156.97 \mathrm{~m} / \mathrm{z}$ corresponds to the daughter fragment $[\mathrm{M}-\mathrm{PhSeH}]^{+}$ resulting from cleavage of the $\mathrm{Se}-\mathrm{Se}$ bond of $\mathrm{PhSeSePh}$. Comparison of the spectrum with that of an authentic sample of $\mathrm{PhSeSePh}$ confirmed the behavior of fragmentation for the diselenide (Supporting Information). This data is in accordance with all previously performed experiments and verifies that the diselenide is the only product formed upon treatment of organoselenols with HNO. 
Computational Analysis. All experimental data indicates that unlike thiols, which are susceptible to both disulfide and sulfinamide modifications by HNO, the reactivity of HNO with selenols leads to the diselenide modification only. To evaluate this finding further, calculations were performed to determine the lowest energy intermediates and transition states for the potential pathways of the reaction of $\mathrm{PhSeH}$ and $\mathrm{HNO}$ to either the corresponding diselenide or proposed seleninamide (end products analogous to thiols). Previously, McCulla and co-workers reported a comprehensive computational analysis of the probable pathways for the reaction of several thiols, including $\mathrm{PhSH}$ with HNO to form either the corresponding disulfide or sulfinamide (Scheme 2) ${ }^{43}$

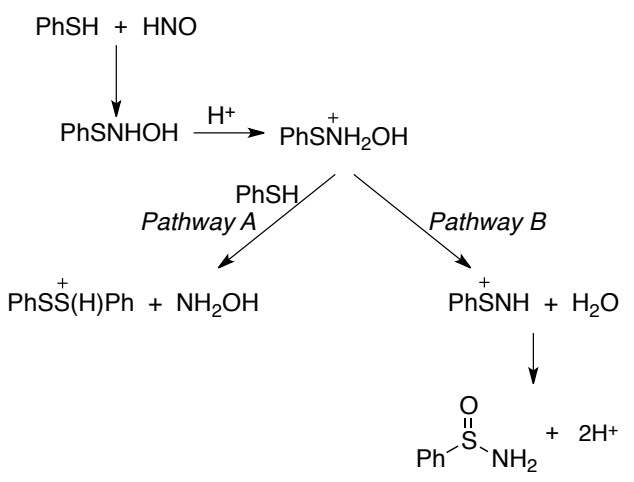

Scheme 2: Proposed pathways leading from the reaction of $\mathrm{PhSH}$ and $\mathrm{HNO}$ to the rearranged sulfinamide and/or the corresponding disulfide.

The calculated geometries in this previous study were used as a starting point for a computational analysis of the reaction of selenols with HNO. Values for the lowest energy intermediates and transition states calculated at the B3LYP/6-31G(d, p) level of theory (Supporting Information) for reactions involving PhSH and HNO (Scheme 2) were in good agreement with those reported by McCulla and co-workers. Calculations 
were then performed for the reaction pathways leading from the reactions of $\mathrm{PhSeH}(\mathbf{1})$ with HNO (Scheme 3).

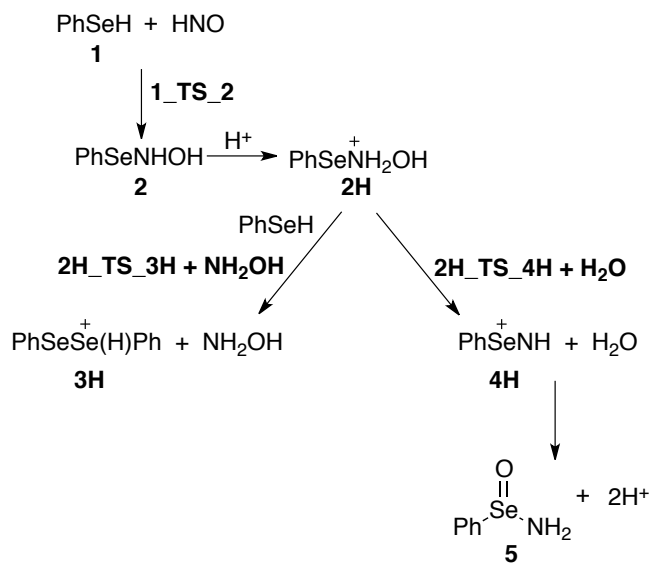

Scheme 3: Proposed pathways leading from the reaction of $\mathrm{PhSeH}(\mathbf{1})$ and $\mathrm{HNO}$ to the rearranged seleninamide $\mathbf{5}$ and/or the corresponding protonated diselenide $\mathbf{3 H}$.

Calculations performed for the initial reaction of $\mathrm{HNO}$ with $\mathrm{PhSH}$ or $\mathrm{PhSeH}$ (Figure 5a) indicate that the relative energy barrier to the transition state for $\mathrm{PhSeH}+$ $\mathrm{HNO}(37.5 \mathrm{kcal} / \mathrm{mol})$ is about $4 \mathrm{kcal} / \mathrm{mol}$ lower than that for $\mathrm{PhSH}+\mathrm{HNO}(41.6$ $\mathrm{kcal} / \mathrm{mol})$. In addition, the $N$-hydroxyselenenamide intermediate $(\mathrm{PhSeNHOH})$ is calculated to be $1.29 \mathrm{kcal} / \mathrm{mol}$ below the reactants $(\mathrm{PhSeH}+\mathrm{HNO})$, whereas the analogous $N$-hydroxysulfenamide $(\mathrm{PhSNHOH})$ is calculated to be $0.65 \mathrm{kcal} / \mathrm{mol}$ above the reactants $(\mathrm{PhSH}+\mathrm{HNO})$. These data indicate that the reaction of $\mathrm{HNO}$ with selenols is favored, both kinetically and thermodynamically, over the analogous reaction with thiols. 

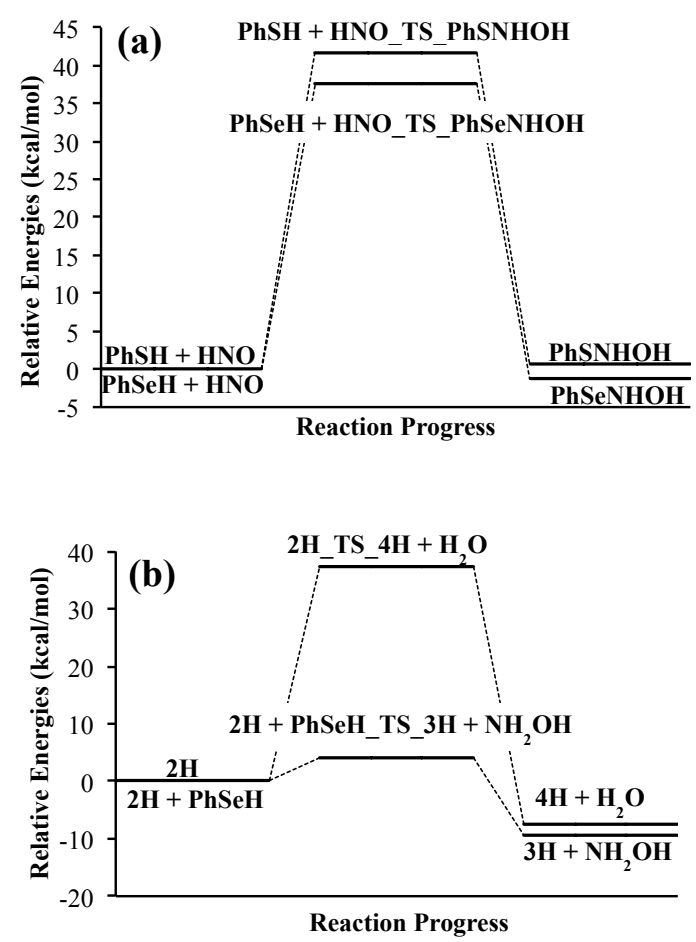

Figure 5: Relative energy diagrams for the reactions involving HNO and thiols/selenols. (a) Initial reaction of $\mathrm{HNO}$ with $\mathrm{PhSH}$ and $\mathrm{PhSeH}$. The energy barrier for the reaction of $\mathrm{PhSH}$ with $\mathrm{HNO}$, to form the $N$-hydroxybenzenesulfenamide intermediate $(+0.65 \mathrm{kcal} / \mathrm{mol}$ relative to $\mathrm{PhSH}+\mathrm{HNO})$ is 41.6 $\mathrm{kcal} / \mathrm{mol}$. The energy barrier for the reaction of $\mathrm{PhSeH}$ with $\mathrm{HNO}$ to form the $\mathrm{N}$ hydroxybenzeneselenenamide intermediate $(-1.3 \mathrm{kcal} / \mathrm{mol}$ relative to $\mathrm{PhSeH}+\mathrm{HNO})$ is $37.5 \mathrm{kcal} / \mathrm{mol}$. (b) Two possible pathways leading from the protonated $N$-hydroxybenzeneselenenamide intermediate $\mathbf{2 H}$ (Scheme 3). The energy barrier for the elimination of water from $\mathbf{2 H}$ to form intermediate $\mathbf{4 H}$ (Scheme 3 ) is $37.2 \mathrm{kcal} / \mathrm{mol}$, and the barrier for nucleophilic attack of the $N$-hydroxyselenenamide intermediate $\mathbf{2 H}$ by another equivalent of $\mathrm{PhSeH}$ to form $\mathbf{3 H}+\mathrm{NH}_{2} \mathrm{OH}$ is $3.9 \mathrm{kcal} / \mathrm{mol}$.

As determined computationally by McCulla and co-workers, the $\mathrm{N}$ hydroxysulfenamide intermediate is predicted to have a $\mathrm{pK}_{\mathrm{a}}$ that ranges from 11.7 to 15.3 (depending on the substituent) and therefore, under neutral $\mathrm{pH}$ conditions, protonation of this intermediate is expected. Analogous protonation of the $N$-hydroxyselenenamide 
intermediate $\mathbf{2}$ leads to $\mathbf{2 H}$, which may be expected to follow two pathways: (1)

rearrangement to the corresponding seleninamide 5 or (2) nucleophilic attack by a second equivalent of $\mathrm{PhSeH}$ to form the corresponding diselenide $\mathbf{3 H}$ (Scheme 3). The energy barriers for the initial step in the rearrangement of $\mathbf{2 H}\left(\mathbf{2 H} \mathbf{H}_{-} \mathbf{T S} \_\mathbf{4 H}+\mathbf{H}_{2} \mathbf{O}\right)$ versus that for nucleophilic attack of $\mathbf{2 H}$ by $\mathrm{PhSeH}\left(\mathbf{2 H} \_\mathbf{T S} \_3 \mathbf{H}+\mathbf{N H} \mathbf{H}_{\mathbf{2}} \mathbf{O H}\right)$ are shown in Figure 5b. These calculated barriers indicate that rearrangement of $\mathbf{2 H}$ to $\mathbf{4 H}(37.2 \mathrm{kcal} / \mathrm{mol})$ is kinetically disfavored in comparison to nucleophilic attack by $\mathrm{PhSeH}(3.9 \mathrm{kcal} / \mathrm{mol})$. Formation of $\mathbf{3 H}+\mathrm{NH}_{2} \mathrm{OH}(-9.4 \mathrm{kcal} / \mathrm{mol})$ is also thermodynamically favored, though only slightly, in comparison to formation of $\mathbf{4 H}+\mathrm{H}_{2} \mathrm{O}(-7.6 \mathrm{kcal} / \mathrm{mol})$. Analogous calculations performed for reactions involving $\mathrm{PhSH}$ (Supporting Information) indicate that nucleophilic attack of the $\mathrm{PhSNH}_{2} \mathrm{OH}^{+}$species by $\mathrm{PhSH}$ is also kinetically favored over rearrangement of $\mathrm{PhSNH}_{2} \mathrm{OH}^{+}$to $\mathrm{PhSNH}^{+}+\mathrm{H}_{2} \mathrm{O}(9.8 \mathrm{kcal} / \mathrm{mol}$ vs. $31.3 \mathrm{kcal} / \mathrm{mol}$, respectively); however, formation of the rearranged species, $\mathrm{PhSNH}^{+}+\mathrm{H}_{2} \mathrm{O}$, is thermodynamically favored over formation of the protonated disulfide, $\mathrm{PhSS}(\mathrm{H}) \mathrm{Ph}^{+}(-$ $19.1 \mathrm{kcal} / \mathrm{mol}$ vs. $2.9 \mathrm{kcal} / \mathrm{mol}$, respectively). Overall, the computational data implies that reactivity of $\mathrm{HNO}$ with $\mathrm{PhSeH}$ is both kinetically and thermodynamically favored over analogous reactions with $\mathrm{PhSH}$ and that $\mathrm{HNO}$-induced modification of selenols favors, again both kinetically and thermodynamically, formation of the diselenide over rearrangement to the seleninamide.

\section{Discussion}

The ability of HNO to target thiols and thiol-containing proteins makes it reasonable to consider selenols and selenoproteins as additional potential targets for 
HNO. Indeed, the work presented here indicates that like thiols, selenols are also targets for $\mathrm{HNO}$; however, unlike thiols, selenols appear to be resistant towards long-term, irreversible HNO-induced modification. In other words, whereas HNO-induced modification of thiols can lead to either reversible-type disulfide (at limited HNO concentrations) or irreversible-type sulfinamide (with excess HNO concentrations) modifications, HNO-induced modification of selenols appears to be exclusively reversible. All conditions studied herein indicate that HNO-induced modification of selenols results in formation of the diselenide product only. There is no evidence supporting rearrangement of the putative $N$-hydroxyselenenamide intermediate to the corresponding seleninamide species. This is consistent with the findings of ${ }^{77} \mathrm{Se}$ NMR, HPLC, and ESI-MS analyses, which all identified the corresponding diselenides as the only product formed upon treatment of selenols with HNO. Such reactivity appears to be a unique characteristic of selenols (in comparison to thiols) and may serve as a potential protective mechanism for selenols and selenol-containing proteins against HNO-induced irreversible modification.

Although the current study only examined those reactions involving small organoselenium molecules with $\mathrm{HNO}$, it is not unreasonable to assume that such findings stand as a viable model to represent similar reactions of selenoproteins towards HNO. For example, due to its GPx-like reactivity, the small organoselenium molecule Ebselen (2-phenyl-1,2-benzoselenazol-3-one) has been used as a chemical model to study the reactivity of GPx towards hydroperoxides. ${ }^{44-46}$ Since its discovery, a number of chemical derivatives, including $o$-nitrophenylselenol (used in the current study) have been synthesized to increase the specificity of such compounds towards hydro- and 
alkylhydroperoxides. ${ }^{46-49}$ In this regard, it appears likely that the results presented herein using small organoselenium compounds are representative of the interactions that can be anticipated for selenoproteins with HNO.

It remains to be seen whether selenol species are generally resistant to biologically irreversible modification by other oxidants in addition to HNO. That is, are selenoproteins particularly resistant to over-oxidation by biological oxidants, perhaps a reason that certain proteins contain a selenocysteine as opposed to a normal cysteine residue? The initial step in the proposed catalytic cycle of the selenoenzyme GPx involves oxidation of the active site selenocysteine residue by hydroperoxides, forming a selenenic acid intermediate $(\mathrm{GPx}-\mathrm{SeOH}, \mathrm{Eq} 1) .^{48,50,51}$ The selenenic acid then undergoes nucleophilic attack by the reducing thiol, glutathione (GSH), forming a selenenyl sulfide intermediate(GPx-SeSG, Eq 2). ${ }^{52}$ This intermediate can be reduced back to the active form of the enzyme (GPx-SeH) via nucleophilic attack by a second equivalent of GSH (Eq 3). GSH thereby acts to resolve hydroperoxide-induced oxidation of the GPx-selenol and prevents its overoxidation to seleninic and/or selenonic acid species. It should be noted that in addition to the previously described catalytic mechanism, some have considered that in the presence of excess hydroperoxide, the selenenic acid intermediate can be overoxidized to the seleninic acid (GPx-Se(O)OH, Eq 4), thus reducing enzymatic activity. ${ }^{53}$ However to date, overoxidation of the selenenic acid has yet to be observed in an in vivo setting and therefore, may prove to be an irrelevant or inaccessible biological modification of selenols and selenoproteins. 


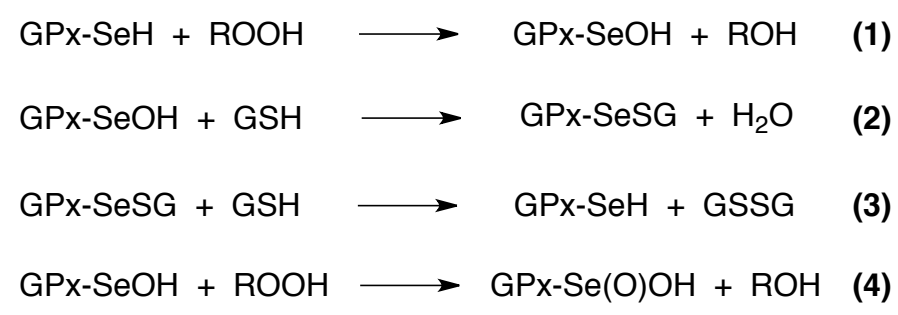

This behavior of GPx is similar to that observed in the current study of organoselenols. Upon treatment of selenols with $\mathrm{HNO}$, the initial reaction is thought to result in an $N$-hydroxyselenenamide intermediate. Rearrangement of this species to a seleninamide is presumed to be an irreversible modification of the selenol species. Instead, all evidence indicates that the $N$-hydroxyselenenamide intermediate is more succeptible to nucleophilic attack by a second equivalent of selenol rather than rearrangement, thus preventing it from being overoxidized. Such findings are in accordance with previously observed behaviors of selenoproteins in biological systems. Combination of this work with that of previous work regarding seleno-compounds, suggests that Nature may choose to use selenium because it has an inherent resistance towards overoxidation/irreversible modification. This ability allows it to maintain its function in biological systems to act as a cell's major line of defense against unwanted overoxidation, even during times of oxidative stress.

\section{Conclusion}

The current work confirms that selenols are a viable target of HNO. Under similar conditions, comparison of the reactivity of thiol species versus analogous selenols indicates that selenols are a more potent trap for HNO. Previously, it has been determined that reactions involving thiols and HNO result in both reversible and 
irreversible thiol modification (depending on relative concentrations); however, the current study demonstrates that reactions of organoselenols and $\mathrm{HNO}$ result in reversible diselenide products only. Such a characteristic is unique to selenols and selenoproteins and may represent a protective mechanism against unwanted modification or overoxidation for these selenols. This would not be surprising considering the important roles of selenoproteins in redox signaling and antioxidant systems. Irreversible modification of selenoenzymes would result in long-term loss of function, which would undoubtedly be detrimental to cellular health, especially during bouts of oxidative stress. The finding that selenoproteins are especially reactive towards oxidants such as $\mathrm{H}_{2} \mathrm{O}_{2}$ or HNO and yet are difficult to modify irreversibly by these same oxidants may represent the true utility of selenium and selenoproteins. However, this is speculative at this time and will require further study before such an idea can be confirmed. 


\section{References}

(1) Flores-Santana, W.; Salmon, D. J.; Donzelli, S.; Switzer, C. H.; Basudhar, D.; Ridnour, L.; Cheng, R.; Glynn, S. a; Paolocci, N.; Fukuto, J. M.; Miranda, K. M.; Wink, D. A. Antioxid. Redox Signal. 2011, 14, 1659-1674.

(2) Tocchetti, C. G.; Stanley, B. A.; Murray, C. I.; Sivakumaran, V.; Donzelli, S.; Mancardi, D.; Pagliaro, P.; Gao, W. D.; van Eyk, J.; Kass, D. A.; Wink, D. A.; Paolocci, N. Antioxid. Redox Signal. 2011, 14, 1687-1698.

(3) Paolocci, N.; Katori, T.; Champion, H. C.; St John, M. E.; Miranda, K. M.; Fukuto, J. M.; Wink, D. A.; Kass, D. A. Proc. Natl. Acad. Sci. U. S. A. 2003, 100, 55375542.

(4) Sabbah, H. N.; Tocchetti, C. G.; Wang, M.; Daya, S.; Gupta, R. C.; Tunin, R. S.; Mazhari, R.; Takimoto, E.; Paolocci, N.; Cowart, D.; Colucci, W. S.; Kass, D. A. Circ. Heart Fail. 2013, 6, 1250-1258.

(5) Miranda, K. M.; Nims, R. W.; Thomas, D. D.; Espey, M. G.; Citrin, D.; Bartberger, M. D.; Paolocci, N.; Fukuto, J. M.; Feelisch, M.; Wink, D. A. J. Inorg. Biochem. 2003, 93, 52-60.

(6) Fukuto, J. M.; Bianco, C. L.; Chavez, T. A. Free Radic. Biol. Med. 2009, 47, $1318-1324$.

(7) Fukuto, J. M.; Carrington, S. J. Antioxid. Redox Signal. 2011, 14, 1649-1657.

(8) Wong, P. S.; Hyun, J.; Fukuto, J. M.; Shirota, F. N.; DeMaster, E. G.; Shoeman, D. W.; Nagasawa, H. T. Biochemistry 1998, 37, 5362-5371.

(9) Donzelli, S.; Espey, M. G.; Thomas, D. D.; Mancardi, D.; Tocchetti, C. G.; Ridnour, L. A.; Paolocci, N.; King, S. B.; Miranda, K. M.; Lazzarino, G.; Fukuto, J. M.; Wink, D. A. Free Radic. Biol. Med. 2006, 40, 1056-1066.

(10) Doyle, M. P. J. Am. Chem. Soc. 1988, 110, 1-37.

(11) DeMaster, E. G.; Redfern, B.; Nagasawa, H. T. Biochem. Pharmacol. 1998, 55, 2007-2015.

(12) Shoeman, D. W.; Shirota, F. N.; Demaster, E. G.; Nagasawa, H. T. Alcohol 2000, 20, 55-59.

(13) Lopez, B. E.; Wink, D. A.; Fukuto, J. M. Arch. Biochem. Biophys. 2007, 465, 430436. 
(14) Keceli, G.; Toscano, J. P. Biochemistry 2012, 51, 4206-4216.

(15) Froehlich, J. P.; Mahaney, J. E.; Keceli, G.; Pavlos, C. M.; Goldstein, R.; Redwood, A. J.; Sumbilla, C.; Lee, D. I.; Tocchetti, C. G.; Kass, D. A.; Paolocci, N.; Toscano, J. P. Biochemistry 2008, 47, 13150-13152.

(16) Jönsson, T. J.; Murray, M. S.; Johnson, L. C.; Poole, L. B.; Lowther, W. T. Biochemistry 2005, 44, 8634-8642.

(17) Jönsson, T. J.; Murray, M. S.; Johnson, L. C.; Lowther, W. T. J. Biol. Chem. 2008, 283, 23846-23851.

(18) Muttenthaler, M.; Alewood, P. F. J. Pept. Sci. 2008, 14, 1223-1239.

(19) Lu, J.; Holmgren, A. J. Biol. Chem. 2009, 284, 723-727.

(20) Arthur, J. R. Cell. Mol. Life Sci. 2000, 57, 1825-1835.

(21) Sengupta, R.; Holmgren, A. Antioxid. Redox Signal. 2012, 18, 259-269.

(22) Pearson, R. G.; Sobel, H.; Songstad, J. J. Am. Chem. Soc. 1985, 89, 319-326.

(23) Nauser, T.; Dockheer, S.; Kissner, R.; Koppenol, W. H. Biochemistry 2006, 45, 6038-6043.

(24) Gettins, P.; Wardlaw, S. A. J. Biol. Chem. 1991, 266, 3422-3426.

(25) Duddeck, H. Prog. Nucl. Magn. Reson. Spectrosc. 1995, 27, 1-323.

(26) Hayashi, S.; Nakanishi, W. Phosphorus, Sulfur, and Silicon 2008, 183, 10671071.

(27) Lewis, E. S.; Yousaf, T. I.; Douglas, T. A. J. Am. Chem. Soc. 1987, 109, $2152-$ 2156.

(28) Aizawa, K.; Nakagawa, H.; Matsuo, K.; Kawai, K.; Ieda, N.; Suzuki, T.; Miyata, N. Bioorganic Med. Chem. Lett. 2013, 23, 2340-2343.

(29) Toscano, J. P.; Brookfiled, F. A.; Cohen, A. D.; Courtney, S. M.; Frost, L. M.' Kalish, V. J. N-Hydroxysulfonamide Derivatives as New Physiologically Useful Donors. U.S. Patent 8,030,356, 2011.

(30) Hughes, M. N.; Cammack, R. Methods Enzymol. 1999, 301, 279-287.

(31) Li, J.; Sha, Y. Molecules 2008, 13, 1111-1119. 
(32) Haratake, M.; Matsumoto, S.; Ono, M.; Nakayama, M. Bioconjug. Chem. 2008, 19, 1831-1839.

(33) C̆asar, Z.; Leban, I.; Maréchal, A. M.; Lorcy, D. J. Chem. Soc. Perkin Trans. 1 2002, 1568-1573.

(34) Ellman, G. L. Arch. Biochem. Biophys. 1959, 82, 70-77.

(35) Fehling, C.; Friedrichs, G. J. Am. Chem. Soc. 2011, 133, 17912-17922.

(36) Sha, X.; Isbell, T. S.; Patel, R. P.; Day, C. S.; King, S. B. J. Am. Chem. Soc. 2006, $128,10958-10963$.

(37) Shoman, M. E.; Dumond, J. F.; Isbell, T. S.; Crawford, J. H.; Brandon, A.; Honovar, J.; Vitturi, D. A.; White, C. R.; Patel, R. P.; King, S. B. J. Med. Chem. 2011, 54, 1059-1070.

(38) Miranda, K. M.; Paolocci, N.; Katori, T.; Thomas, D. D.; Ford, E.; Bartberger, M. D.; Espey, M. G.; Kass, D. A.; Feelisch, M.; Fukuto, J. M.; Wink, D. A. Proc. Natl. Acad. Sci. 2003, 100, 9196-9201.

(39) Jackson, M. I.; Han, T. H.; Serbulea, L.; Dutton, A.; Ford, E.; Miranda, K. M.; Houk, K. N.; Wink, D. A.; Fukuto, J. M. Free Radic. Biol. Med. 2009, 47, 11301139.

(40) Milne, J. Magn. Reson. Chem. 1993, 655, 652-655.

(41) Luthra, N. P.; Dunlap, R. B.; Odom, J. D. J. Magn. Reson. 1983, 52, 318-322.

(42) Shao, Y.; Molnar, F.; Jung, Y.; Brown, S. T.; Gilbert, A. T. B.; Slipchenko, L. V; Levchenko, S. V; Neill, D. P. O.; Jr, A. D.; Rohini, C.; Wang, T.; Beran, G. J. O.; Besley, N. A.; John, M.; Lin, Y.; Voorhis, T. Van; Chien, H.; Sodt, A.; Steele, P.; Rassolov, V. A.; Maslen, P. E.; Korambath, P. P.; Adamson, D.; Austin, B.; Baker, J.; Byrd, E. F. C.; Dachsel, H.; Doerksen, R. J.; Dreuw, A.; Dunietz, B. D.; Dutoi, A. D.; Furlani, T. R.; Gwaltney, S. R.; Heyden, A.; Hirata, S.; Hsu, P.; Kedziora, G.; Khalliulin, R. Z.; Klunzinger, P.; Aaron, M.; Lee, M. S.; Liang, W.; Lotan, I.; Nair, N.; Peters, B.; Proynov, E. I.; Pieniazek, P. A.; Rhee, M.; Ritchie, J.; Sherrill, C. D.; Simmonett, A. C.; Subotnik, J. E.; Lee, H.; Iii, W.; Zhang, W.; Bell, A. T.; Chakraborty, A. K.; Daniel, M.; Keil, F. J.; Warshel, A.; Hehre, W. J.; Schaefer, H. F.; Kong, J.; Krylov, A. I.; Gill, M. W.; Head-gordon, M. Phys. Chem. Chem. Phys. 2006, 8, 3172-3191.

(43) Sherman, M. P.; Grither, W. R.; McCulla, R. D. J. Org. Chem. 2010, 75, 40144024.

(44) Parnham, M. J.; Sies, H. Biochem. Pharmacol. 2013, 86, 1248-1253. 
(45) Sarma, B. K.; Mugesh, G. Chem. Eur. J. 2008, 14, 10603-10614.

(46) Mugesh, G. Curr. Chem. Biol. 2013, 7, 47-56.

(47) Mugesh, G.; Panda, A.; Singh, H. B.; Punekar, N. S.; Butcher, R. J.; V, H. U.; December, R. V; Re, V.; Recei, M.; October, V. J. Am. Chem. Soc. 2001, 123, 839-850.

(48) Dowd, D.; Gettins, P. Magn. Reson. Chem. 1988, 26, 1-3.

(49) Chaudiere, J.; Courtin, O.; Leclaire, J. Arch. Biochem. Biophys. 1992, 296, 328336.

(50) Chaudiere, J.; Wilhelmsen, E. C.; Tappel, a. L. J. Biol. Chem. 1984, 259, 10431050 .

(51) Bhowmick, D.; Mugesh, G. Org. Biomol. Chem. 2015, 13, 10262-10272.

(52) Epp, O.; Ladenstein, R.; Wendel, A. Eur. J. Biochem. 1983, 133, 51-69.

(53) Wendel, A.; Pilz, W.; Ladenstein, R.; Sawatzki, G.; Weser, U. Biochim. Biophys. Acta 1975, 377, 211-215. 